02

\title{
Спектроскопические исследования изменений во вторичной структуре белков дентинной и десневой жидкостей по данным синхротронной ИК микроскопии
}

\author{
(С) П.В. Середин ${ }^{1}$, Д.Л. Голощапов ${ }^{1}$, Ю.А. Ипполитов ${ }^{2}$, Jitraporn (Pimm) Vongsvivut $^{3}$ \\ ${ }^{1}$ Воронежский государственный университет, \\ 394036 Воронеж, Россия \\ ${ }^{2}$ Воронежский государственный медицинский университет им. Н.Н. Бурденко, \\ 394036 Воронеж, Россия \\ ${ }^{3}$ Australian Synchrotron (Synchrotron Light Source Australia Pty LTD), \\ VIC 3168, Australia \\ e-mail: paul@phys.vsu.ru
}

Поступила в редакцию 14.05.2019 г.

В окончательной редакции 24.07.2019 г.

Принята к публикации 12.08.2019 г.

На основе данных ИК спектромикроскопии с использованием синхротронного излучения проведено исследование вторичной структуры белков дентинной и десневой жидкостей человека при развитии кариозного процесса в глубоких тканях дентина. Показано, что изменение формы профиля полосы Амид I в области $1700-1605 \mathrm{~cm}^{-1}$ связано как с изменением соотношения интегральных интенсивностей вторичных структур $\alpha$-спираль и $\beta$-лист, так и положением компонент $\beta$-витки и $\beta$-лист в спектре. Установлено, что величина соотношения $\alpha$-спираль/ $\beta$-лист как для дентинной, так и десневой жидкостей лежит ниже порогового уровня, при котором наблюдаются значительные изменения во вторичной структуре белков биологических жидкостей и однозначно свидетельствует о развитии патологии в твердой ткани. Обнаруженные нами особенности в профиле полосы Амид I биологических жидкостей ротовой полости совместно со спектральными маркерами развития кариозного процесса в дентине являются достоверными спектроскопическими сигнатурами патологии и могут быть детектированы с использованием десневой жидкости.

Ключевые слова: ИК микроскопия, синхротронное излучение, кариес дентина, спектроскопические сигнатуры патологических процессов.

DOI: $10.21883 /$ OS.2019.12.48686.159-19

\section{Введение}

Одной из значимых и все еще нерешенных проблем терапевтической стоматологии является задача эффективной персонализированной диагностики патологических процессов в тканях дентина зубов человека [1]. Современные исследования показывают, что обнаружение инфицированного, склеротичного и измененного дентина возможно лишь на поздних стадиях развития кариеса $[2,3]$. Несвоевременное обнаружение патологических процессов в глубоких тканях дентина зачастую ведет к утрате части или всего зуба, а также является угрозой здоровья человека в целом [4-6]. Поэтому так активно развиваются методики раннего обнаружения патологий дентина методами оптической спектроскопии, основанных на скрининге препарированных тканей зубов [7-10]. Одновременно с этим обращают на себя внимание научные работы, в которых возникновение воспалительных процессов в ротовой полости детектируется с использованием носителей маркеров патологий (воспаления) - биологических жидкостей. В случае превентивной диагностики заболеваний дентина кариозного характера идеальным кандидатом на роль объекта скрининга может выступить дентинная жидкость, которая играет весомую роль в развитии кариеса дентина [11]. Однако трудоемкость и практическая невозможность забора дентинной жидкости in vivo [12] является главным препятствием развития нового направления диагностики. Иссечение тканей эмали для забора дентинной жидкости, является нецелесообразным в случае, например, фиссурного кариеса, когда речь идет об определении наличия воспалительного процесса в дентине. Поэтому скрининг развития патологий в дентине требует определения воспалительных факторов в других биологических жидкостях ротовой полости - слюне, крови и жидкости из десневой борозды $[13,14]$.

Извлечение жидкости из десневой борозды для диагностики патологий дентина является более простой задачей, a ее молекулярный анализ, с последующим выделением маркеров развития кариозного процесса в дентине, может быть выполнен с использованием техники молекулярной идентификации [13,15-17]. Для данных задач наиболее информативным и прецизионным методом, позволяющим регистрировать изменения мо- 


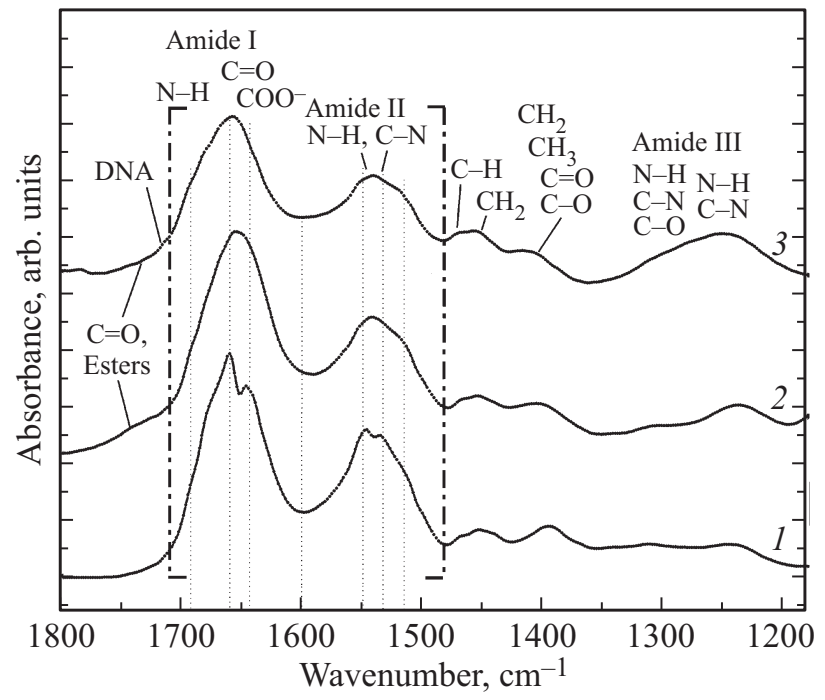

Рис. 1. ИК спектры образцов крови (1), десневой (2) и дентинной (3) жидкостей человека. Вертикальными штрихпунктирными линиями обозначен диапазон проявления характеристических особенностей альбумина и глобулинов.

лекулярного состава объектов биологической природы, является ИК спектроскопия [18-21]. С использованием метода ИК спектроскопии могут быть зарегистрированы изменения, происходящие во вторичной структуре биологических жидкостей ротовой полости, т.е. в пространственной структуре их белков, при развитии определенной патологии [22,23]. В ряде передовых работ, посвященных поиску математических алгоритмов анализа спектральных полос амидных групп, уже продемонстрированы перспективы развития этого подхода для скрининга изменений в протеоме ротовой жидкости человека при развитии заболеваний $[24,25]$. Привлечение для этого данных высокоразрешающей ИК спектроскопии позволило, в частности, проанализировать уровень кариесорезистентности у пациентов с множественным кариесом [26]. В рамках описанного подхода на основе расчета минерал/органического, углерод/фосфатного, амидного и иных соотношений, определенных из данных математического анализа колебательных полос в ИК спектрах, появляется возможность проанализировать изменения, происходящие в белково/органической составляющей биологических жидкостей ротовой полости, а также определить стадию развития патологии твердых тканей зубов и парадонта [21,25-27].

Следует отметить, что в литературе нет информации о сопоставлении молекулярного состава дентинной и десневой жидкостей, а также данных об изменениях, происходящих в конформационном окружении их белков, при развитии патологических изменений в тканях дентина. Поэтому целью нашей работы стал поиск изменений во вторичной структуре белков дентинной и десневой жидкостей на основе данных их спектроскопических исследований.

\section{Материалы и методы исследования}

В исследовании приняли участие 10 человек (5 мужчин и 5 женщин) в возрасте 22-28 лет. От каждого пациента с детектированным кариесом дентинабыли взяты три образца биологических жидкостей: дентинная жидкость, жидкость из десневой борозды и кровь из десны. Забор образцов биологических жидкостей ротовой полости был выполнен с использованием специализированной вакуумной установки и разработанных нами микрокапилляров, заполненных гомогенизированным порошком $\mathrm{KBr}$. После забора образцов порошок $\mathrm{KBr}$ из микрокапилляров, содержащих биологические жидкости, высушивался при комнатной температуре.

Исследования молекулярного состава образцов дентинной жидкости, десневой жидкости и крови из десны человека были выполнены с использованием методики ИК спектроскопии с привлечением оборудования канала Инфракрасной Микроспектроскопии (IRM) (Австралийский синхротрон, Мельбурн, Австралия), спектрометра Bruker Vertex 80V с детектором, охлаждаемым жидким азотом (Bruker Optik GmbH, , Германия) [28].

\section{Экспериментальные результаты и их обсуждение}

Анализ полученных методом ИК спектромикроскопии данных показал, что спектры однотипных образцов внутри группы участников эксперимента содержат абсолютно один и тот же набор колебательных мод. При этом в ИК спектрах образцов внутри рассматриваемой экспериментальной группы наблюдались незначительные отличия в изменении интенсивности присутствующих колебательных полос. Поэтому в нашей работе представлены усредненные по группе участников эксперимента спектры образцов биологических жидкостей. Следует отметить, что процедура усреднения спектров по экспериментальной группе позволяет избежать случайных ошибок эксперимента и индивидуальных особенностей лиц в конкретной группе [27].

На рис. 1 приведены ИК спектры поглощения образцов крови, дентинной и десневой жидкостей пациентов в области $1725-1190 \mathrm{~cm}^{-1}$. Выделенная отдельно область амидных полос $1710-1470 \mathrm{~cm}^{-1}$ указывает регион в ИК спектрах, используемый для анализа вторичной структуры белковой составляющей биологических жидкостей человека. Выбор границ данной области основан на анализе данных из работ [22-24], а также определен с учетом влияния колебаний сложного эфира $\mathrm{C}=\mathrm{O}\left(1740 \mathrm{~cm}^{-1}\right)$ и ДНК/РНК структур $\left(1725 \mathrm{~cm}^{-1}\right)$ на форму амидных полос. Анализ полученных данных и расшифровка ИК спектров были выполнены на основе литературных источников, в которых методом FTIR исследовались образцы биологических жидкостей ротовой полости, белки и аминокислоты [24,29-37]. Список активных колебаний в ИК спектрах образцов крови, дентинной и десневой жидкостей, а также частоты этих 
Таблица 1. Активные колебания в спектрах образцов крови, дентинной и десневой жидкостей пациентов. Интенсивности колебательных полос в спектрах: +- слабая; ++- средняя, +++- сильная, ++++- очень сильная

\begin{tabular}{|c|c|c|c|c|c|c|}
\hline \multirow{2}{*}{$\begin{array}{c}\text { Принадлежность к } \\
\text { молекулярной группе }\end{array}$} & \multirow{2}{*}{ Мода колебаний } & \multirow{2}{*}{$\begin{array}{c}\text { Частота } \\
\text { колебаний, } \mathrm{cm}^{-1}\end{array}$} & \multicolumn{3}{|c|}{ Биологическая жидкость } & \multirow{2}{*}{$\begin{array}{c}\text { Источник } \\
\text { данных }\end{array}$} \\
\hline & & & Кровь & $\begin{array}{c}\text { Дентинная } \\
\text { жидкость }\end{array}$ & $\begin{array}{l}\text { Десневая } \\
\text { жидкость }\end{array}$ & \\
\hline $\begin{array}{l}\text { Карбоновая группа } \\
\text { эфира и ДНК }\end{array}$ & $\begin{array}{l}\text { >C=O валентные, } \\
\mathrm{C}=\mathrm{O} \text { валентные, } \\
\text { характеристическая } \\
\text { парно-базовая } \\
\text { компонента ДНК }\end{array}$ & $1738-1713$ & - & + & ++ & {$[15,27,30,32,36]$} \\
\hline $\begin{array}{l}\text { Белки } \\
\text { вторичной структуры }\end{array}$ & $\beta$-витки и $\beta$-листы & 1684 & ++ & ++ & ++ & {$[24,36,37]$} \\
\hline $\begin{array}{l}\text { Белки } \\
\text { вторичной структуры }\end{array}$ & Амид I $\beta$-спираль & 1663 & ++++ & ++++ & ++++ & {$[24,29-32,37]$} \\
\hline Белки & $\begin{array}{l}\text { Амид I C=O валентные } \\
\text { и Амид II N-H } \\
\text { деформационные }\end{array}$ & $1647-1642$ & ++++ & ++++ & ++++ & {$[24,29-31,38]$} \\
\hline $\begin{array}{l}\text { Белки, триптофан, } \\
\text { метгемоглобин }\end{array}$ & $\begin{array}{l}\text { Амид II, валентные CN } \\
\text { и CNH деформационные }\end{array}$ & $1548-1544$ & +++ & +++ & +++ & {$[24,29-32,37]$} \\
\hline $\begin{array}{l}\text { Белки } \\
\text { Амид II, гуанин }\end{array}$ & $v \mathrm{C}=\mathrm{N}, v \mathrm{C}=\mathrm{C}$ & $1530-1525$ & +++ & +++ & +++ & {$[24,29,32,37]$} \\
\hline Белки, каротиноиды & $\begin{array}{l}\text { СН деформационные; } \\
\text { v }=\mathrm{C} ; \text { Амид II }\end{array}$ & $1514-1504$ & ++ & ++ & ++ & {$[24,30,37,38]$} \\
\hline $\begin{array}{l}\text { Боковые цепи аминокислот, } \\
\text { липиды и белки }\end{array}$ & $\begin{array}{l}\text { Асимметричные } \\
\text { деформационные } \mathrm{CH}_{2}\end{array}$ & $1469-1455$ & ++ & +++ & ++ & {$[24,29,30,32,37]$} \\
\hline $\begin{array}{l}\text { Фибриноген, боковые } \\
\text { цепи аминокислот, } \\
\text { липиды и белки }\end{array}$ & $\begin{array}{l}\text { Симметричные } \mathrm{CH}_{3} \\
\text { деформационные, } \mathrm{COO} \\
\text { валентные }\end{array}$ & $1412-1396$ & ++ & ++ & ++ & {$[24,29,30,32,37]$} \\
\hline Белки & Амид III C-N валентные & $1312-1310$ & + & ++ & + & {$[24,29,37]$} \\
\hline $\begin{array}{l}\text { Фосфодиэфирные } \\
\text { группы в ДНК, белки }\end{array}$ & $\begin{array}{l}\mathrm{P}=\mathrm{O} \text { of } \mathrm{PO}_{2} \text { - валентные, } \\
\text { Амид III Асимметричные } \\
\mathrm{C}-\mathrm{N} \text { валентные }\end{array}$ & $1250-1240$ & + & +++ & ++ & {$[24,29-31,37]$} \\
\hline
\end{tabular}

колебательных мод и их принадлежность к конкретной молекулярной группе представлены в табл. 1.

Из полученных нами экспериментальных данных (рис. 1, табл. 1) следует, что среди группы колебательных полос белков в ИК спектрах образцов крови, дентинной и десневой жидкостей могут быть выделены полосы вторичных амидов: Амид I (валентные колебания $\mathrm{C}=\mathrm{O}$ в области $1725-1590 \mathrm{~cm}^{-1}$ ), Амид II (N-H-деформационные и $\mathrm{C}-\mathrm{N}$ - валентные колебания в области $1590-1500 \mathrm{~cm}^{-1}$ ) и Амид III (C-N-деформационные, $\mathrm{N}-\mathrm{H}$-деформационные в области 1350-1190 $\mathrm{cm}^{-1}$ ), а также колебания $\mathrm{CH}_{2} / \mathrm{CH}_{3}$ групп, расположенные в области $1480-1350 \mathrm{~cm}^{-1}$ [38].

Отметим, что применение высококогерентного синхротронного излучения позволяет разрешить спектральные особенности амидных полос с большей точно- стью $[28,37,39]$. Поэтому в наших экспериментальных спектрах, например в спектре крови (рис. 1, кривая 1), можно наблюдать ряд особенностей у колебаний Амид I и Амид II, которые относятся к компонентам белковой фракции крови: альбумину и глобулинам [22,29,30,40]. Эти особенности, наблюдаемые как ряд дополнительных плеч у основных интенсивных колебательных мод, обозначены на рис. 1 вертикальными пунктирными линиями. Полученные нами данные о различном спектральном положении колебательных полос альбумина и глобулина находятся в согласии с результатами работ [32,40].

\section{Анализ вторичной структуры белков}

Как показывает анализ публикаций последних лет, изучение белковых структур с использованием ИК спектроскопии и последующий математический ана- 


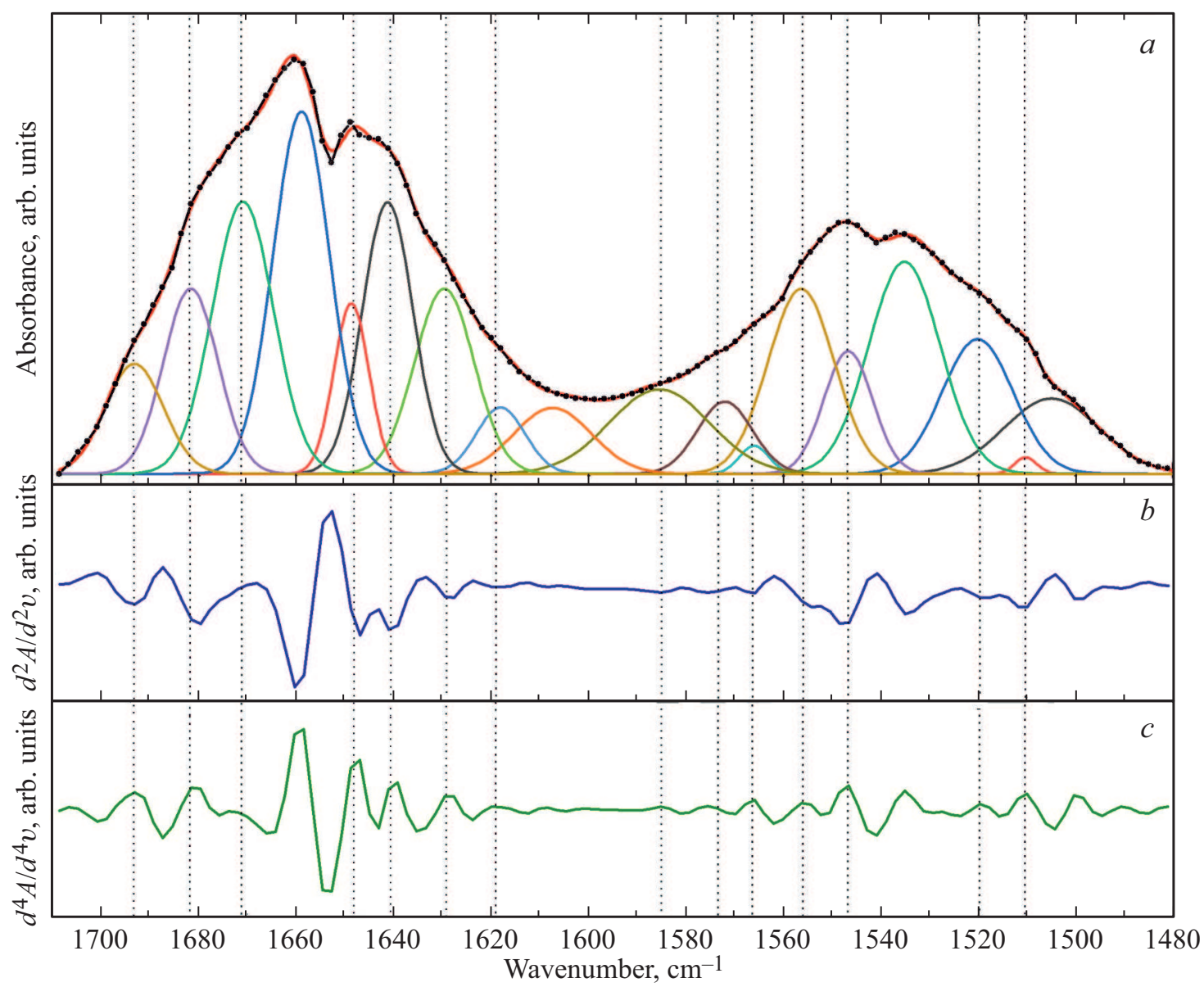

Рис. 2. (a) - модельный и экспериментальный ИК спектры в области $1710-1480 \mathrm{~cm}^{-1}$, с гауссовыми компонентами, для образца крови, полученной из десны зуба с диагностированным кариесом дентина, $(b)-$ вторая производная экспериментального ИК спектра, $(c)$ - четвертая производная экспериментального ИК спектра.

лиз спектрального профиля амидных полос (Амид I, Амид II и Амид III), позволяет установить зависимость интенсивности компонент вторичной структуры белков от их пространственной структуры [41]. Поэтому область $1750-1300 \mathrm{~cm}^{-1}$ в экспериментальных ИК спектрах биологических жидкостей ротовой полости (рис. 1, кривые 1,2,3) является предметом тщательного изучения [32,40]. Наличие или отсутствие ферментов, липидов, факторов воспаления и других структур в биологических жидкостях влияет на вторичную структуру их белков и, в свою очередь, отражается на профиле амидных полос в ИК спектрах [42]. Поэтому изменение в конформации белка (пространственной конфигурации белковой молекулы), регистрируемое методом ИК спектромикроскопии, может быть связано с конкретным типом воспалительного процесса [39], что весьма ценно для ранней диагностики широкого ряда заболеваний человека [22,41,43-45].

Как уже было отмечено ранее, изменения в молекулярном составе биологических жидкостей, в частности во вторичной структуре их белков, наиболее явным образом находят свое отражение в ИК спектрах в виде особенностей в формы колебательных полос, относимых к Амид I и Амид II [40]. Поэтому в нашей работе для определения изменений во вторичной структуре белков образцов крови, дентинной и десневой жидкостей, взятых у пациентов с патологией глубоких тканей дентина кариозного характера, полосы Амид I и Амид II были разложены на компоненты с использованием гауссовых кривых. Пример такого разложения для образца крови представлен на рис. 2, $a$. При этом для выделения компонент в экспериментальном профиле использовались математические алгоритмы определения экстремумов с использованием второй и четвертой производной (рис. 2, $b, c$ ). Результаты моделирования, число компонент в модельном спектре и обнаруженные спектральные особенности сопоставлялись с данными из известных работ по анализу вторичной структуры белков сыворотки крови и десневой жидкости $[23,32,41]$.

Важно отметить, что для анализа вторичной структуры белков мы детально рассмотрели только область $1605-1710 \mathrm{~cm}^{-1}$ полосы Амид I, поскольку входящие в нее связи $\mathrm{C}=\mathrm{O}$ и $\mathrm{C}-\mathrm{N}$ являются наиболее чувствительными к локальным изменениям, происходящим 
Таблица 2. Компоненты вторичной структуры белков в полосе Амид I и их частоты колебаний $\left(\mathrm{cm}^{-1}\right)$ для образцов сыворотки крови, десневой и дентинной жидкостей человека

\begin{tabular}{|c|c|c|c|c|c|}
\hline \multirow[b]{2}{*}{$\mathrm{N}$} & \multirow{2}{*}{$\begin{array}{l}\text { Компоненты вторичной } \\
\text { структуры полосы Амид I }\end{array}$} & \multicolumn{3}{|c|}{ Биологическая жидкость } & \multirow[b]{2}{*}{ Источник данных } \\
\hline & & Кровь & $\begin{array}{l}\text { Десневая } \\
\text { жидкость }\end{array}$ & $\begin{array}{l}\text { Дентинная } \\
\text { жидкость }\end{array}$ & \\
\hline $\mathrm{I}\left(\mathrm{A}_{\mathrm{I}}\right)$ & Аминокислотная боковая цепь & 1607.4 & 1610.1 & 1608.0 & {$[35,38,41-43]$} \\
\hline II $\left(\mathrm{A}_{\mathrm{II}}\right)$ & Аминокислотная боковая цепь & 1618.1 & 1618.1 & 1618.1 & {$[22,35,42,43]$} \\
\hline $\mathrm{III}\left(\beta_{\mathrm{III}}\right)$ & $\beta$-складчатый слой & 1629.6 & 1629.6 & 1627.7 & {$[39,41,43]$} \\
\hline $\mathrm{IV}\left(\beta_{\mathrm{IV}}\right)$ & $\beta$-складчатый слой & 1641.3 & 1639.1 & 1637.4 & {$[38,41-43]$} \\
\hline $\mathrm{V}\left(\mathrm{R}_{\mathrm{V}}\right)$ & Неупорядоченная структура & 1648.7 & 1648.3 & 1648.9 & {$[38,41-43]$} \\
\hline $\mathrm{VI}\left(\alpha_{\mathrm{VI}}\right)$ & $\alpha$-спираль & 1658.9 & 1658.1 & 1658.6 & {$[38,41-43]$} \\
\hline VII $\left(\mathrm{T}_{\mathrm{VII}}\right)$ & $\beta$-виток & 1672.1 & 1668.5 & 1668.5 & {$[38,41-43]$} \\
\hline VIII $\left(\beta_{\mathrm{VIII}}\right)$ & $\beta$-лист антипаралельный $+\beta$-виток & 1681.7 & 1681.7 & 1681.7 & {$[22,35,42,43]$} \\
\hline $\mathrm{IX}\left(\beta_{\mathrm{IX}}\right)$ & $\beta$-лист антипаралельный & 1693.3 & 1693.3 & 1695.2 & {$[22,35,42,43]$} \\
\hline
\end{tabular}

в молекулярном составе и окружении биологических жидкостей человека. При этом в начальном приближении для построения модельных спектров биологических жидкостей ротовой полости принимались во внимание известные соотношения между компонентами вторичной структуры белка $[22,42,44,46]$. Разложение спектров на компоненты производилось по предложенной и опробованной в ряде работ методике $[22,24,44]$ с учетом накладываемых ограничений и критических замечаний, касающихся вычисления количества максимумов в спектре, проведения фоновой линии и определения сходимости результата разложения [23]. Выработанный алгоритм математической обработки спектральных данных позволил найти необходимый критерий сходимости и воспроизводимости результатов моделирования, а также обеспечил однозначность разложения полосы Амид I у исследуемых образцов.

Следует отметить, что при анализе вторичной структуры белков и изменений в ней существует необходимость рассмотрения полного профиля ИК полосы Амид I [24]. Это обусловлено тем фактом, что при разложении лишь части профиля ИК полосы соотношение интенсивностей мод колебаний, относимых к компонентам $\alpha$-спираль и $\beta$-лист в структуре вторичных белков, может быть двукратно искажено [23]. В сложных случаях для корректных расчетов учет слабых спектральных особенностей возможен только при полнопрофильном анализе полосы $[23,24]$. Поэтому для изучаемых биологических жидкостей мы провели полнопрофильный анализ полосы Амид I с учетом полосы Амид II (рис. 2, $a$ ).

Обратим внимание на тот факт, что диапазон $1660-1649 \mathrm{~cm}^{-1}$ является сложным для моделирования и часто соответствует перекрытию нескольких полос $\alpha$ спирали во вторичной структуре белков. Так, в работе [23] было показано, что при моделировании данной области без разделения $\alpha$-спирали на компоненты достичь в модельных кривых однозначного соответствия между моделью и экспериментальным спектром не удается. Поэтому в нашем расчете $\alpha$-спираль приводится как сумма двух высокоинтенсивных максимумов.

Анализируя полученные результаты моделирования, следует отметить следующие обнаруженные важные особенности. Тонкая структура полосы Амид I крови человека определяется в основном смешением альбуминовой (основной компоненты в составе) и глобулиновой фракции [22,40,45]. Как было показано в работе [42], при смешивании альбумина с ДНК и РНК происходит сдвиг полос вторичной структуры белков, поэтому в табл. 2 мы привели интервалы частот, где наблюдаются характеристические компоненты полосы Амид I, полученные в ходе обработки экспериментальных данных изучаемых биологических жидкостей.

Что же касается возможных частотных сдвигов в положении компонент вторичной структуры, относимых к $\beta$-виток и $\beta$-лист, то необходимо отметить, что данные компоненты слабо разрешимы, их форма и вид в каждом отельном случае зависят от многих факторов. Поэтому при проведении разложения экспериментального спектра согласно рекомендациям из [23] мы опирались не только на условие сходимости модельной и экспериментальной кривой (рис. $3, a, b, c$ ) и их производных (рис. $3, f, e, d)$, но также, как указывается в ряде работ [24,41-43], на наименьшее количество максимумов, с использованием которых, в пределах ошибки, можно провести моделирование.

Нужно сказать, что представленные на рис. $3, f, e, d$ графики производных экспериментальных и модельных кривых демонстрируют удовлетворительное соответствие в пределах точности эксперимента. Наибольшая разница между кривыми наблюдается на краях рассмат- 

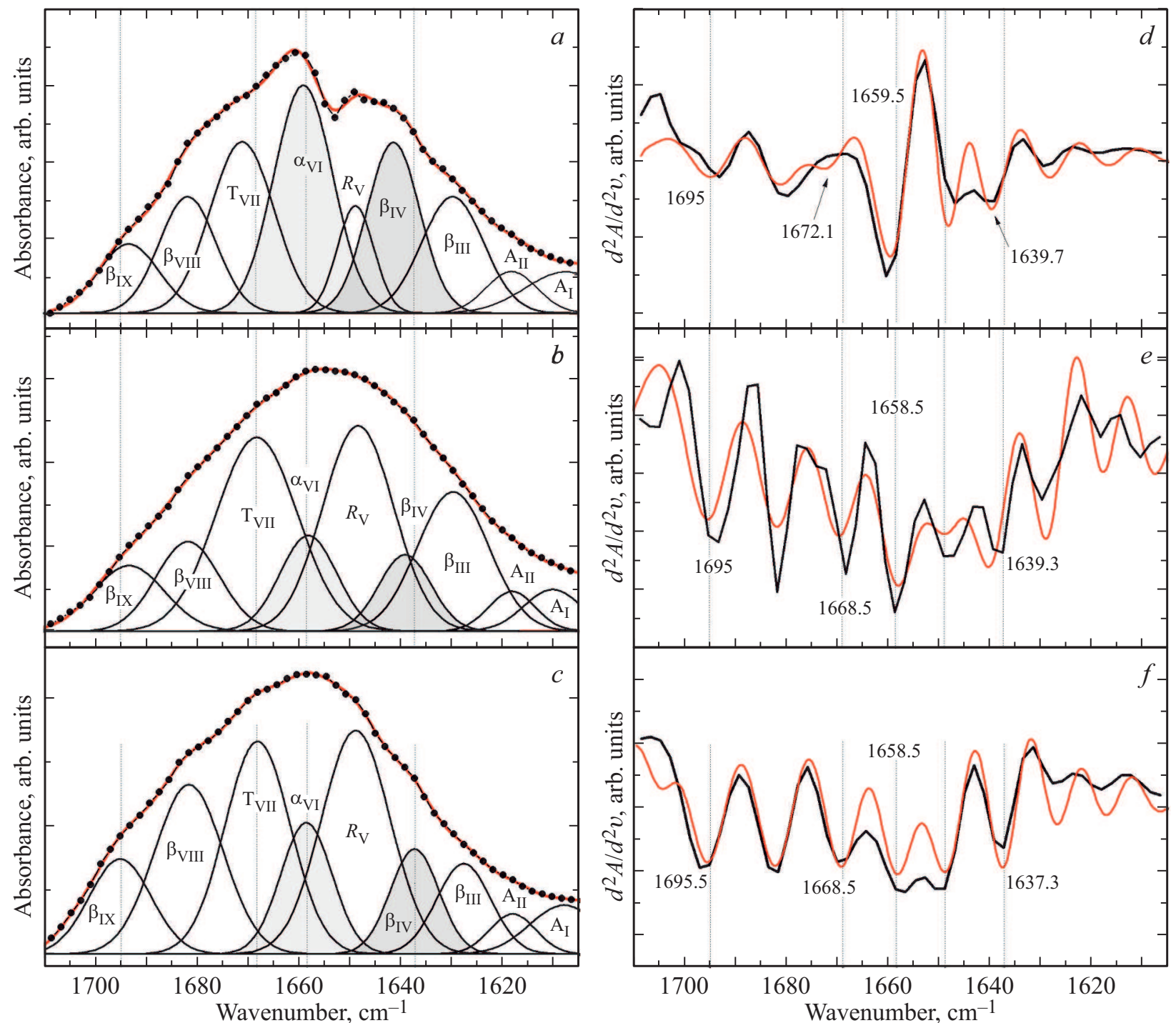

Рис. 3. Экспериментальная (точки) и модельная (красная кривая) полоса Амид I, ее гауссовы компоненты (слева, $a-c)$, вторая производная экспериментальной (черные линии) и модельной (красные линии) полосы Амид I (справа, $d-f$ ) в спектрах образцов крови из десны человека $(a, d)$, жидкости из десневой борозды $(b, e)$, дентинной жидкости $(c, f)$.

риваемой области: 1700 и $1610 \mathrm{~cm}^{-1}$. Этот факт объясняется выбором для моделирования гауссовой функции, а также нелинейностью фона и статистическими особенностями экспериментального спектра.

\section{Анализ и обсуждение полученных результатов}

Результаты разложения полосы Амид I на компоненты для образцов крови, дентинной и десневой жидкостей (pис. $3, a, b, c$ и табл. 2) показывают, что положение основных компонент вторичной структуры белков в этих образцах практически не изменяется. Данный факт обусловлен тем, что дентинная и десневая жидкости являются производными плазмы крови и схожи с ней по составу глобулярных белков. Единственное значимое смещение во вторичной структуре белков обнаруживается для компоненты $\beta_{\mathrm{IV}}$-складчатый слой, которая в спектре дентинной жидкости сдвинута на $4 \mathrm{~cm}^{-1}$ в низкочастотную сторону относительно положения этой компоненты в ИК спектре образцов крови (табл. 2). Также смещение наблюдается и для компоненты $\beta_{\mathrm{VIII}^{-}}$ витки, которая в спектре дентинной жидкости расположена около $1668.5 \mathrm{~cm}^{-1}$, а в спектре образцов крови локализована около $1672.1 \mathrm{~cm}^{-1}$. Результаты, представленные в табл. 2 , показывают, что аналогичную тенденцию частотного сдвига компонент $\beta$-витки и $\beta$-лист можно обнаружить и у образцов десневой жидкости, относительно образца крови.

Как следует из работы [42], подобные сдвиги положения компонент вторичной структуры белка, например альбумина сыворотки крови человека (одной из составляющих всех исследуемых жидкостей), могут наблюдаться в присутствии определенных ферментов. Принимая во внимание данный факт, необходимо отме- 
тить, что в спектрах дентинной и десневой жидкостей присутствуют моды сложного эфира, локализованные в области $1738 \mathrm{~cm}^{-1}$, что свидетельствует о кариесогенной патологии [27]. Поэтому частотный сдвиг компонент вторичной структуры $\beta$-витки и $\beta$-лист в спектре дентинной и десневой жидкостей может быть связан с изменением их молекулярного состава при развитии кариеса дентина.

Детальное рассмотрение полосы Амид I всех образцов (рис. $3, a, b, c)$ показывает, что основные изменения формы профиля обусловлены перераспределением интенсивностей компонент вторичной структуры белков $\alpha$-спираль, случайная спираль, $\beta$-витки и $\beta$-складчатый слой. Несмотря на достаточно большое процентное содержание неупорядоченных структур $-\mathrm{R}_{\mathrm{V}}$, положение компоненты $\alpha$-спираль в спектрах образцов биологических жидкостей практически не изменятся ( $1658 \mathrm{~cm}^{-1}$, табл. 2), что отражает близость состава всех рассматриваемых жидкостей. С другой стороны, количественное содержание компонент белковой фракции в биологических жидкостях может различаться ввиду взаимодействия десневой и дентинной жидкостей с пораженными кариесом твердыми тканями зуба. Поэтому интенсивность компоненты $\alpha$-спираль по отношению к другим компонентам в полосе Amid I может изменяться (рис. 3, $a, b, c)$.

Анализ данных математического моделирования показывает, что при развитии патологий дентина кариозного характера в образцах крови, десневой и дентинной жидкостях процентное содержание компоненты $\alpha$-спираль $\left(\alpha_{\%}\right)$ во вторичной структуре белка не изменяется. Величина $\alpha_{\%}$ лежит в пределах $28 \%$ (кровь)-31\% (десневая жидкость)- $32 \%$ (дентинная жидкость), что значительно ниже той, которая наблюдается в норме для белка сыворотки крови (HSA) и должна быть в пределах 50-60\% [44,47,48]. Данный факт является весомым индикатором изменений во вторичной структуре белка, сигнализируя о конформационных трансформациях, происходящих в органической составляющей биологических жидкостей пациентов при развитии кариеса дентина.

В то же время расчет важного для белков соотношения $\alpha$-спираль/ $\beta$-лист показал, что наибольшие изменения во вторичной структуре наблюдаются в дентинной жидкости. В самом деле, соотношение $\alpha$-спираль/ $\beta$-лист, как это было показано Jitto Titus и соавторами [22], является статистически значимым маркером развития воспалительных процессов. В работе [44] на примере альбумина сыворотки крови человека было доказано, что возникновение внутримолекулярных структур $\beta$ лист, связано с агрегацией белковых молекул, что, в свою очередь, отрицательно сказывается на функционировании белка. Математическая оценка спектральных данных для образцов сыворотки крови, проведенная в работе [22], показала, что в результате скрининга воспалительных процессов при развитии артрита соотношение $\alpha$-спираль/ $\beta$-лист для вторичной структуры белка должно принимать значения ниже уровня 3.9. Полученные нами результаты показывают, что коэффициент $\alpha$ спираль/ $\beta$-лист для образца крови принимает значение $\alpha_{\mathrm{VI}} / \beta_{\mathrm{IV}}=1.5$, для десневой жидкости $\alpha_{\mathrm{VI}} / \beta_{\mathrm{IV}}=1.32$ и для дентинной жидкости $\alpha_{\mathrm{VI}} / \mathrm{IV}=1.35$, что значительно ниже порогового уровня. Для дентинной жидкости это соотношение принимает самое низкое значение, что связано со значительными изменениями в ее вторичной структуре из-за ее непосредственного контакта с тканью дентина.

Полученные в нашей работе результаты свидетельствуют о том, что развитие патологических процессов кариозного характера в дентине находит свое отражение в составе биологических жидкостей ротовой полости. Определенные изменения во вторичной структуре белка биологических жидкостей являются достоверными спектроскопическими сигнатурами патологии и могут быть легко детектированы без трудоемкого и нецелесообразного извлечения дентинной жидкости, поскольку одновременно присутствуют и в десневой жидкости, забор которой для скрининга не представляет собой столь сложной задачи.

\section{Заключение}

На основе данных математического моделирования полосы Амид I и выделения в ней компонент вторичной структуры белков в образцах крови, десневой и дентинной жидкостей в работе установлено, что развитие патологических процессов кариозного характера в тканях дентина влияет на молекулярный состав биологических жидкостей ротовой полости человека, контактирующих с твердой тканью зуба. Изменение формы экспериментального профиля полосы Амид I связано с перераспределением интегральных интенсивностей компонент $\alpha$-спираль и $\beta$-лист вторичной структуры белка, а также частотным сдвигом компонент $\beta$-витки и $\beta$-лист.

Впервые показано, что во вторичной структуре белков образцов крови, десневой и дентинной жидкости не изменяется процентное содержание компоненты $\alpha$ спираль. Установлено, что $\alpha$-спираль $/ \beta$-лист соотношение, рассчитанное из анализа вторичной структуры белков дентинной и десневой жидкостей, лежит ниже порогового уровня, при котором характерны значительные изменения во вторичной структуре белков биологических жидкостей человека, что в свою очередь однозначно свидетельствует о развитии патологии в тканях дентина.

Обнаруженные нами особенности в профиле колебательной полосы Амид I биологических жидкостей ротовой полости, совместно с обнаруженными спектральными маркерами развития кариозного процесса в дентине являются достоверными спектроскопическими сигнатурами патологии и могут быть легко детектированы на основе анализа только десневой жидкости. 


\section{Благодарности}

The part of this research was undertaken with The Infrared Microspectroscopy (IRM) beamline at the Australian Synchrotron.

\section{Финансирование}

Исследование выполнено за счет гранта Российского научного фонда (проект № 16-15-00003).

\section{Соблюдение этических стандартов}

Все процедуры, выполненные в исследовании с участием людей, соответствуют этическим стандартам Хельсинкской декларации 1964 года и ее последующим изменениям или сопоставимым нормам этики. От каждого из включенных в исследование участников было получено информированное добровольное согласие.

\section{Конфликт интересов}

Авторы заявляют, что у них нет конфликта интересов

\section{Список литературы}

[1] Liu Y., Yao X., Liu Y.W., Wang Y. // Caries Res. 2014. V. 48. N 4. P. 320. doi $10.1159 / 000356868$

[2] Ribeiro Figueiredo A.C., Kurachi C., Bagnato V.S. // Caries Res. 2005. V. 39. N 5. P. 393. doi $10.1159 / 000086846$

[3] Almahdy A., Downey F.C., Sauro S., Cook R.J., Sherriff M., Richards D., Watson T.F., Banerjee A., Festy F. // Caries Research. 2012. V. 46. N 5. P. 432. doi 10.1159/000339487

[4] Rôças I.N., Alves F.R.F., Rachid C.T.C.C., Lima K.C., Assunção I.V., Gomes P.N., Siqueira J.F. // PLoS One. 2016. V. 11. N 5. doi 10.1371/journal.pone.0154653

[5] Tanner A.C., Kressirer C., Faller L., Lake K., Dewhirst F., Kokarasb A., Paster B., Frias-Lopez J. // J. Oral Microbiology. 2017. V. 9. N supl. 1. P. 1325194. doi 10.1080/20002297.2017.1325194

[6] Slimani A., Nouioua F., Panayotov I., Giraudeau N., Chiaki K., Shinji Y., Cloitre T., Levallois B., Gergely C., Cuisinier F., Tassery H. // International J. Experimental Dental Science. 2016. V. 5. N 1. P. 1.

doi 10.5005/jp-journals-10029-1115

[7] Salehi H., Terrer E., Panayotov I., Levallois B., Jacquot B., Tassery H., Cuisinier F. // J. Biophotonics. 2012. V. 6. N 10. P. 1. doi 10.1002/jbio.201200095

[8] Seredin P., Goloshchapov D., Prutskij T., Ippolitov Y. // PLoS ONE. 2015. V. 10. N 4. P. 1. doi 10.1371/journal.pone. 0124008

[9] Seredin P.V., Goloshchapov D.L., Prutskij T., Ippolitov Yu.A. // Opt. Spectrosc. 2018. V. 125. N 5. P. 803.

doi 10.1134/S0030400X18110267

[10] Chen Q.G., Zhu H.H., Xu Y., Lin B., Chen H. // Laser Physics. 2015. V. 25. N 8. P. 085601 doi 10.1088/1054-660X/25/8/085601

[11] Love R.M., Jenkinson H.F. // Critical Reviews in Oral Biology \& Medicine. 2002. V. 13. N 2. P. 171.

doi $10.1177 / 154411130201300207$
[12] Geraldeli S., Li Y., Hogan M.M.B., Tjaderhane L.S., Pashley D.H., Morgan T.A., Zimmerman M.B., Brogden K.A. // Arch. Oral Biol. 2012. V. 57. N 3. P. 264. doi 10.1016/j.archoralbio.2011.08.012

[13] Barros S.P., Williams R., Offenbacher S., Morelli T. // Periodontol. 2000. 2016. V. 70. N 1. P. 53. doi 10.1111/prd.12107

[14] Gao X., Jiang S., Koh D., Hsu C.-Y.S. // Periodontol. 2000. 2016. V. 70. N 1. P. 128. doi 10.1111/prd.12100

[15] Xiang X.M., Liu K.Z., Man A., Ghiabi E., Cholakis A., Scott D.A. // J. Periodontal Research. 2010. V. 45. N 3. P. 345. doi 10.1111/j.1600-0765.2009.01243.x

[16] Gupta G. // J. Med Life. 2013. V. 6. N 1. P. 7-13. PMID: 23599812

[17] Carneiro L.G., Nouh H., Salih E. // J. Clinical Periodontology. 2014. V. 41. N 8. P. 733. doi $10.1111 /$ jcpe. 12262

[18] Shaw R.A., Mantsch H.H. Infrared Spectroscopy in Clinical and Diagnostic Analysis // Encyclopedia of Analytical Chemistry. John Wiley \& Sons, Ltd, 2006. P. 20.

[19] Xiang X., Duarte P.M., Lima J.A., Santos V.R., Gonçalves T.D., Miranda T.S., Liu K.-Z. // J. Periodontology. 2013. V. 84. N 12. P. 1792. doi 10.1902/jop.2013.120665

[20] Avraamova O.G., Ippolitov Y.A., Plotnikova Y.A., Seredin P.V., Goloshapov D.V., Aloshina E.O. // Stomatologiia (Mosk). 2017. V. 96. N 2. P. 6-11. PMID: 28514339

[21] Seredin P., Goloshchapov D., Kashkarov V., Ippolitov Y., Bambery K. // Results in Physics. 2016. V. 6. P. 315. doi 10.1016/j.rinp.2016.06.005

[22] Titus J., Ghimire H., Viennois E., Merlin D., Perera A.G.U. // J. Biophotonics. 2018. V. 11. N 3. P. e201700057. doi 10.1002/jbio.201700057

[23] Baldassarre M., Li C., Eremina N., Goormaghtigh E., Barth A., Baldassarre M., Li C., Eremina N., Goormaghtigh E., Barth A. // Molecules. 2015. V. 20. N 7. P. 12599. doi 10.3390/molecules200712599

[24] Júnior C., Cesar P., Strixino J.F., Raniero L., Júnior C., Cesar P., Strixino J.F., Raniero L. // Research on Biomedical Engineering. 2015. V. 31. N 2. P. 116. doi 10.1590/2446-4740.0664

[25] Elangovan S., Margolis H.C., Oppenheim F.G., Beniash E. // Langmuir. 2007. V. 23. N 22. P. 11200. doi 10.1021/la7013978

[26] Fujii S., Sato S., Fukuda K., Okinaga T., Ariyoshi W., Usui M., Nakashima K., Nishihara T., Takenaka S. // Anal Sci. 2016. V. 32. N 2. P. 225. doi 10.2116/analsci.32.225

[27] Seredin P., Goloshchapov D., Ippolitov Y., Vongsvivut P. // EPMA Journal. 2018. V. 9. N 2. P. 195. doi 10.1007/s13167-018-0135-9

[28] Vongsvivut J., Pérez-Guaita D., Wood B.R., Heraud P., Khambatta K., Hartnell D., Hackett M.J., Tobin M.J. // Analyst. 2019. doi 10.1039/c8an01543k

[29] Makhnii T., Ilchenko O., Reynt A., Pilgun Y., Kutsyk A., Krasnenkov D., Ivasyuk M., Kukharskyy V. // Ukrainian J. Physics. 2016. V. 61. N 10. P. 853. doi 10.15407/ujpe61.10.0853

[30] Lopes J., Correia M., Martins I., Henriques A.G., Delgadillo I., da Cruz e Silva O., Nunes A. // J. Alzheimer?s Disease. 2016. V. 52. N 3. P. 801. doi 10.3233/JAD-151163

[31] Orphanou C. $-M$. // Forensic Science International. 2015. V. 252. P. e10. doi 10.1016/j.forsciint.2015.04.020

[32] Matthäus C., Bird B., Miljković M., Chernenko T., Romeo M., Diem M. // Methods Cell Biol. 2008. V. 89. P. 275. doi 10.1016/S0091-679X(08)00610-9 
[33] Badea I., Crisan M., Fetea F., Socaciu C. // Romanian Biotechnological Letters. 2014. V. 19. N 6. P. 9817.

[34] Workman J., Weyer L. Practical guide and spectral atlas for interpretive near-infrared spectroscopy. 2nd Edition. CRC Press, 2012. 209 p.

[35] Barth A. // Biochimica et Biophysica Acta (BBA) Bioenergetics. 2007. V. 1767. N 9. P. 1073. doi 10.1016/j.bbabio.2007.06.004

[36] Elkins K.M. // J. Forensic Sciences. 2011. V. 56. N 6. P. 1580. doi 10.1111/j.1556-4029.2011.01870.x

[37] Seredin P.V., Goloshchapov D.L., Ippolitov Y.A., Kalivradzhiyan E.S. // Russian Open Medical J. 2018. V. 7. N 1. P. e0106. doi 10.15275/rusomj.2018.0106

[38] Kong J., Yu S. // Acta Biochim. Biophys. Sin. (Shanghai). 2007. V. 39. N 8. P. 549-559. PMID: 17687489

[39] Hoffner G., André W., Sandt C., Djian P. // Reviews in Analytical Chemistry. 2014. V. 33. N 4. doi 10.1515/revac-2014-0016

[40] Guaita D.P., Ventura-Gayete J., Rambla C.P., Andreu M.S., de la Guardia M., Mateo S.G. // Analytical and Bioanalytical Chemistry. 2012. V. 404. N 3. P. 649. doi $10.1007 / \mathrm{s} 00216-012-6030-7 \mathrm{~N}$

[41] Stuart B.H. Infrared Spectroscopy of Biological Applications // Encyclopedia of Analytical Chemistry. American Cancer Society, 2006. P. 31.

[42] Tajmir-Riahi H.A., N'soukpoé-Kossi C.N., Joly D. // Spectroscopy. 2009. V. 23. N 2. P. 81. doi 10.3233/SPE-2009-0371

[43] Yang H., Yang S., Kong J., Dong A., Yu S. // Nature Protocols. 2015. V. 10. N 3. P. 382. doi 10.1038/nprot.2015.024

[44] Huang Y.-T., Liao H.-F., Wang S.-L., Lin S.-Y. // AIMS Biophysics 2016. V. 3. P. 247. doi 10.3934/biophy.2016.2.247

[45] Depciuch J., Sowa-Kućma M., Nowak G., Dudek D., Siwek M., Styczeń K., Parlińska-Wojtan M. // J. Pharmaceutical and Biomedical Analysis. 2016. V. 131. P. 287. doi 10.1016/j.jpba.2016.08.037

[46] Petibois C., Gionnet K., Gonçalves M., Perromat A., Moenner M., Déléris G. // Analyst. 2006. V. 131. N 5. P. 640. doi 10.1039/B518076G

[47] Guo H., Huang F., Li Y., Fang T., Zhu S., Chen Z. // Analytical Letters. 2016. V. 49. N 18. P. 2964. doi 10.1080/00032719.2016.1166507

[48] de Cássia Fernandes Borges R., Navarro R.S., Giana H.E., Tavares F.G., Fernandes A.B., Silveira L., Jr. // Research on Biomedical Engineering. 2015. V. 31. N 2. P. 160. doi 10.1590/2446-4740.0593 